\title{
Variations in the Prevalence of Obesity Among European Countries, and a Consideration of Possible Causes
}

\author{
John E. Blundell ${ }^{a} \quad$ Jennifer Lyn Baker ${ }^{b}$ Emma Boyland ${ }^{c}$ Ellen Blaak ${ }^{d}$ \\ Jadwiga Charzewska ${ }^{e}$ Stefaan de Henauw ${ }^{f}$ Gema Frühbeck ${ }^{g}$ \\ Marcela Gonzalez-Gross ${ }^{h}$ Johannes Hebebrand ${ }^{i}$ Lotte Holm ${ }^{j} \quad$ Vilma Kriaucioniene $^{k}$ \\ Lauren Lissner ${ }^{\prime}$ Jean-Michel Oppert ${ }^{\mathrm{m}}$ Karin Schindler ${ }^{\mathrm{n}} \quad$ Analiza Mónica Silva $^{\circ}$ \\ Euan Woodward ${ }^{p}$ \\ ${ }^{a}$ Institute of Psychological Sciences, Faculty of Medicine and Health, University of Leeds, Leeds,

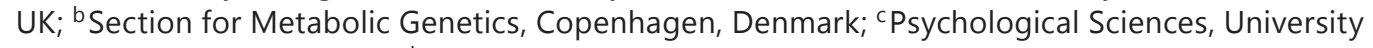 \\ of Liverpool, Liverpool, UK; ${ }^{d}$ Department of Human Biology, NUTRIM School of Nutrition and \\ Translational Research in Metabolism, Maastricht University Medical Centre (MUMC), Maastricht,

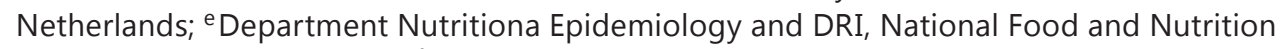 \\ Institute, Warszawa, Poland; ${ }^{f}$ Department of Public Health, Ghent University, Ghent, Belgium; \\ g Metabolic Research Laboratory, Obesity Area, Department of Endocrinology \& Nutrition, Clinica \\ Univ. de Navarra, University of Navarra, Pamplona, Spain; hepartment of Health and Human \\ Performance, Facultad de CC de la Actividad Física y del Deporte-INEF, Universidad Politécnica de \\ Madrid, Madrid, Spain; 'Department of Child and Adolescent Psychiatry, LVR-Klinikum, University \\ Duisburg-Essen, Essen, Germany; ${ }^{j}$ Department of Food and Resource Economics, Consumption, \\ Bioethics and Governance, University of Copenhagen, Frederiksberg C, Denmark; ${ }^{k}$ Faculty of Public \\ Health, Medical Academy, Lithuanian University of Health Sciences, Kaunas Lithuania; 'Section for \\ Epidemiology and Social Medicine (EPSO), Gothenburg, Sweden; 'mService de Nutrition GH Pitié- \\ Salpêtrière, Paris, France; ${ }^{n}$ Abteilung für Endokrinologie und Stoffwechsel, Klinik für Innere Medizin \\ III, Wien, Austria; ${ }^{\circ}$ Laboratory of Physiology and Biochemistry of Exercise, Faculty of Human \\ Kinetics, University of Lisbon, Portugal; ${ }^{\mathrm{P} E A S O}$ Secretariat, Teddington, UK
}

\section{Key Words}

Obesity · Risk factors · Causes

\begin{abstract}
Over the last 10 years the prevalence of obesity across the European continent has in general been rising. With the exception of a few countries where a levelling-off can be perceived, albeit at a high level, this upward trend seems likely to continue. However, considerable country to country variation is noticeable, with the proportion of people with obesity varying by $10 \%$ or more. This variation is intriguing and suggests the existence of different profiles of risk or protection factors operating in different countries. The identification of such protection factors could indicate suitable targets for interventions to help manage the obesity epidem-
\end{abstract}


Blundell et al.: Variations in the Prevalence of Obesity Among European Countries, and a Consideration of Possible Causes

ic in Europe. This report is the output of a 2-day workshop on the 'Diversity of Obesity in Europe'. The workshop included 14 delegates from 12 different European countries. This report contains the contributions and discussions of the materials and viewpoints provided by these 14 experts; it is not the output of a single mind. However, such is the nature of scientific analysis regarding obesity that it is possible that a different set of 14 experts may have come to a different set of conclusions. Therefore the report should not be seen as a definitive statement of a stable situation. Rather it is a focus for discussion and comment, and a vehicle to drive forward further understanding and management of obesity in Europe.

(c) 2017 The Author(s)

Published by S. Karger GmbH, Freiburg

\section{Focus}

Considering the outcomes of successive surveys of the prevalence of overweight and obesity in Europe (such as those carried out by the Global Health Observatory [1]), two distinct features stand out. First, across the whole continent the levels of obesity have been rising inexorably and seemingly continue to do so. Second, there is a very large diversity from country to country within the geographical boundaries of the continent (fig. 1). This diversity is intriguing and the most recent data indicate a variation from low levels of obesity constituting $18-19 \%$ of the population, to high levels of $28-30 \%$. The most likely interpretation of these values is that they signify a differential distribution and pattern of risk and protective factors in different countries. Identifying these factors will throw light on the reasons for the variation and will indicate key national features that could form the targets for policy interventions. In this way the variation in the rates of obesity in Europe represents a real world ongoing experimental laboratory to identify the causes of obesity. This issue was the subject of a multidisciplinary workshop organised by the Scientific Advisory Board (SAB) of the EASO with the backing of WHO Europe, that took place in London on February 22-23, 2016.

\section{Framework}

The initial concept behind the workshop was the possibility of compiling an Obesogenic Scorecard for each country. This would illustrate the existence and the strength of all factors (for which there is evidence or circumstantial evidence) that are obesity-promoting and of those which are protective. A starting point is the recognition that obesity is not caused by a single factor but emerges from a complex system of distinct and interconnecting factors such as those identified in the Obesity Systems Map (fig. 2) [2, 3]. Such factors might include core influences concerning energy intake and expenditure (proximal variables in the systems map) such as food consumption and physical activity patterns - together with modulators such as environmental structures, cultural values, social inequalities, social class differences, economic factors, social gradients, stress and others. Alongside these socio-cultural (or environmental) modulators, certain genetic modulators play a role.

Is this attempt to identify the distribution and potency of susceptibility and protective risk factors for obesity an enterprise worth pursuing? Can this process help to identify - by a process of comparison and juxtaposition - factors specific to particular countries that contribute to the development, maintenance and further promotion of obesity in Europe?

Of course, one could approach the issue by intuition rather than analysis. For example, it is tempting when comparing the relatively low rates of obesity in Belgium, Netherlands and Denmark with the higher rates in Germany, Poland and the UK, to attribute the disparity to 
Blundell et al.: Variations in the Prevalence of Obesity Among European Countries, and a Consideration of Possible Causes

Fig. 1. Spatial representation for adult obesity in Europe for 2014 (WHO data).
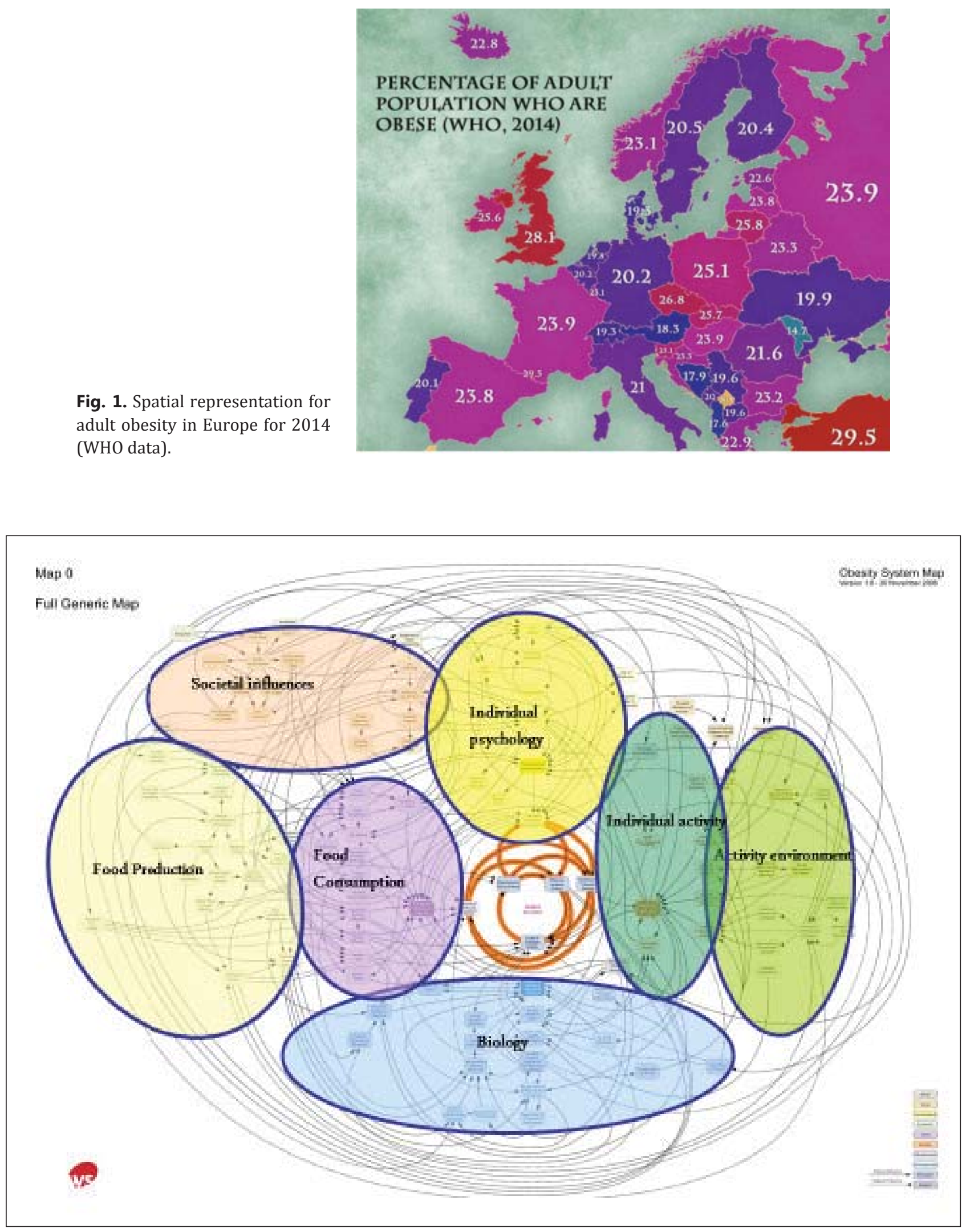

Fig. 2. The Obesity Systems map indicating the complexity of obesities and the major influences influencing weight gain within any society. regarded as a 'complex systems approach' to understanding obesity. 
Blundell et al.: Variations in the Prevalence of Obesity Among European Countries, and a Consideration of Possible Causes

the fact that the former countries comprise geography of largely flat terrain and a social culture in which most people use bicycles as a daily form of public transport - thus ensuring a high level of energy expenditure. Could a factor as obvious and as simple as this constitute a decisive risk factor for obesity? Could this eventuality become more than a plausible perception?

The 14 workshop delegates were drawn from 12 different European countries: Belgium, the Netherlands, Austria, France, Germany, Lithuania, Spain, Portugal Denmark, Sweden, Poland and the UK. The topic areas addressed included: the status of epidemiological data itself, physical activity patterns, nutritional intakes, food choice and eating patterns, environmental factors, sleep habits, genetics and allelic variation, physiology and metabolism, and cultural attitudes. The group included two members of the EASO New Investigators United recognised for their expertise and for their potential to develop careers relevant to the field of obesity. The workshop was intended to be open-minded and exploratory. It was understood from the outset that clear and definite explanations underlying the differences in prevalence might not emerge. However, the enterprise would break new ground by asking a simple question: 'What accounts for the variation in the prevalence of obesity in European countries?'. This article forms a brief report of the workshop and proposes further actions.

\section{How to Interpret the Prevalence Data}

Europe is a large and heterogeneous continent, and a consideration of the differences in prevalence of obesity between different countries constitutes a different type of exercise to the comparison of rates between states of the USA. In Europe, countries differ on the basis of geographical features, climate, language, history, economic matters, cultural traditions, territorial boundaries, social values and habits, food availability and norms about eating, physical features, physiology, and genetic disposition. This immense diversity is immediately detectable when travelling across Europe and provides a rich fabric of possibilities for seeking the origins and maintenance factors for obesity. Such endogenous differences also pose problems for the collection of data regarding BMI and other relevant indices required at the national level. In passing it can be noted at the outset that the status of BMI (the most frequently used index of obesity) can be questioned. BMI fails to account for body composition and fails to distinguish between the relative contribution of fat mass (FM) and fat-free mass (FFM). This issue has been the subject of a previous SAB enquiry [4] and will not be mentioned further. However, it remains an issue when trying to understand the causes of increasing adiposity.

Owing to the remoteness of some countries and the lack of resources for measuring objectively even weight and height, the percent values for some countries are based on selfreported data which may not be nationally representative. It should be noted that these countries record some of the lowest percent values of obesity, which may be an underestimation [5]. It was pointed out therefore that when comparing countries it is important to compare 'like with like'. Ideally, the data should have been collected in a uniform manner using similar procedures and with stratification for age, social class and gender - all of which have a pervasive influence on obesity. With regard to these demographic factors, a question arose about the interpretation of the Global Health Observatory which reported European-wide increases in obesity (with the exception of Italy) between 2010 and 2014. Given the increase in life expectancy and a reduced birth rate, it can be asked whether the increase in percent obesity between 2010 and 2014 represents the operation of a factor that is causing new cases to arise, or whether it may (partially) reflect older populations. Thus, in those countries, in which the mean age has increased during this time period, the increment of the prevalence 
Blundell et al.: Variations in the Prevalence of Obesity Among European Countries, and a Consideration of Possible Causes

rate may at least partially reflect the fact that obesity prevalence rates increase well into the sixth decade of life. It is crucial to take mean age differences of the populations under study into account: Populations with a somewhat older mean age should have higher rates of obesity without this necessarily reflecting a true (age-adjusted) difference.

Whatever the explanation, the data indicate that more individuals are likely to be crossing the obesity threshold of a BMI of $30 \mathrm{~kg} / \mathrm{m}^{2}$ and that people remain for longer periods within the BMI 30+ category. The data clearly indicate that the total 'amount' of obesity in Europe is increasing - either as a function of an ageing population or from a factor that drives people from overweight to obesity; this seems to be operating in all EU countries - and to approximately the same degree (with the exception of Italy).

Concerning the collection of reliable data, the Childhood Obesity Surveillance Initiative (COSI) is gathering consistent data on a national basis and provides a uniform basis for comparisons. However, these data are available for only a handful of countries. National governments are responsible for this data collection, but this obviously involves a cost which may be a deterrent. However, the full extent of the problem of childhood obesity cannot be confronted without strong and reliable statistics. At the present time, although the diversity in percent values of childhood obesity appear to be huge (variations from 12 to 40\%), it is difficult to attribute causes to these figures. However, different definitions of obesity exist for childhood and adolescent obesity. Frequently, BMI centiles are used because the use of an absolute BMI value as a threshold is not possible due to large age-dependent differences in the proportion of youths with a BMI above such a static value. The use of BMI centiles - while clearly advantageous - frequently rests on national reference systems that may not be representative and that potentially date back to different years. Clearly, caution is also warranted when interpreting observed national differences in overweight and obesity rates in children and adolescents [6].

It is important to make the point that differences between countries may depend on factors which are entirely different between the countries. However, the working group agreed that it is more likely that the same factors are in play (perhaps in varied forms) in all countries, Therefore, the way in which these factors are distributed within countries may turn out to be the important issue when explaining national differences. However, it is not possible to rule out the operation of factors that may be truly unique to a particular country.

An important message from our analysis concerns the heterogeneity and sometimes poor quality of data on prevalence across different countries in Europe. Prevalence will vary according to the size of the population surveyed and the mode of data collection. Even within specific countries estimates can vary by as much as $8 \%$ according to the survey method used. A consistent and systematic approach to the collection of data would greatly improve the capacity to understand the epidemic of obesity and its variability from region to region.

\section{National, Regional and Temporal Analyses}

The differences in national prevalence rates for obesity require explanations. However, differences also exist within national boundaries; for example, eastern and western parts of Austria. Within countries there is also often a disparity in prevalence between socio-economic categories; normally there is a lower percentage of obesity in high socio-economic status (SES) regions. However the dynamic nature of obesity is reflected in some observations that the gradient in obesity percentage in lower SES compared with that in high SES groups) is shifting in different countries; the movement appears to be towards a decrease in the size of this gradient. Such a decrease is likely to be due to an increase in the percentage in high SES regions rather than to a decrease in low SES groups. This historical shift is from a negative 
Blundell et al.: Variations in the Prevalence of Obesity Among European Countries, and a Consideration of Possible Causes

association between poverty and obesity to a positive one in rich welfare states. This contrast can still be seen in WHO Europe member states that are conducting childhood obesity surveillance.

This shift in the gradient between social levels may be influenced - as seen earlier for the overall prevalence rates - by ageing populations. However, the variation in obesity between social classes (SES) and its link with poverty (at least in urban areas) will probably be a modulating factor in comparing one country with another. For example, wealthy countries may have a similar percentage of obesity when compared to some economically poorer countries but for quite different reasons. This does not mean that a country by country comparison is invalid; rather that, owing to a major effect of SES, the prevalence data will be greatly informed by knowledge of the prevailing socio-economic conditions.

A further basis for comparison can occur across time periods. For example, it has been reported for Danish data that the calculations of percentage of obesity in different (young) age groups is time-dependent [7]. It seems that the epidemic of childhood obesity has developed in waves. The data indicate that from birth years of 1930 to 1941 the prevalence was low and stable; however, an increase was observed from 1942 to mid-1950s followed by stability (albeit at a higher level) until a sharp increase occurred from 1971 onwards. Similar trends were apparent in Australia and the USA. Although food production (and consumption) could be a plausible force behind such trends, only the national production of pork (in Denmark) was associated with the changes in prevalence. The factors behind the longitudinal trends may give clues to which factors may be operating differently in countries compared at the same time point.

However it is appropriate to mention that certain evidence has pointed to a recent break in the epidemic in children; for instance first in Sweden and then in the last NHANES in the USA [8]. In addition, there is evidence from at least 9 different countries that the prevalence of childhood obesity is plateauing [9]. However, although the prevalence appears to be stabilising, the levels remain disturbingly high. One exception may be the UK which has in operation a 'child measurement programme'. This objective form of surveillance has recently demonstrated that levels of obesity are steadily getting worse. More than 1 in 5 children are obese when they start school, and this has risen to 1 in 3 by the time they leave primary school. Clearly different factors seem to be operating in the UK than in other parts of Europe. This difference can provide a tool for investigation.

\section{Does Genetic Susceptibility to Obesity Vary in Different Countries?}

It is known that there is variation in the prevalence of specific alleles between the north and south of Europe. This raises the possibility that genetic variation between different geographic regions could be linked to obesity. Both before and after genome-wide association studies (GWAS) there has been a strong interest in the impact of genes on obesity. This is based on the recognition that certain aspects of obesity represent heritable traits, with heritability estimates varying between 40 and $70 \%$ depending on the populations examined. The discovery of leptin and the leptin deficiency syndrome encouraged thinking about a genetic basis for obesity. However, it is estimated that only about $5 \%$ of severe obesity is dependent upon the influence of a particular single gene. However, beyond these known single gene defects, approximately 128 alleles have been associated with some parameters related to obesity (visceral fat, waist circumference, insulin resistance etc.). Most of these genes are shown to be connected to CNS activity or structure [10]. It is now clearly recognised that BMI is a polygenic trait. Given that height plays a key role in the calculation of BMI, it may be significant that more than 700 genes are involved in body height. Latest analyses indicate that the 
Blundell et al.: Variations in the Prevalence of Obesity Among European Countries, and a Consideration of Possible Causes

$100+$ genes most closely linked to 'obesity' in large samples account for about $2 \%$ of the variance. Considering the FTO gene alone, two predisposing alleles in contrast to two protective alleles reflect a difference of approximately 1 BMI unit. Moreover, possession of the predisposing alleles does not constitute a biological inevitability for the development of obesity, and it has been demonstrated that the influence of FTO alleles can be counter-acted by a high level of physical activity [11]. Taken together, it is likely that the operation of any genetic factor can be over-ridden or masked by environmental effects [12]. Populationgenetic differences in BMI were recently detected amongst almost 10,000 individuals across 14 European countries. Approximately 8\% (95\% CI 4-16\%) of the captured additive genetic variance for BMI reflected population-genetic differences. Interestingly, a correlated selection for both height and BMI was detected, with a higher height associated with a lower BMI. Environmental differences across Europe masked genetic differentiation for BMI [13].

Epigenetics and its variable effects on numerous phenomena add further complexity. Maternal genetic and phenotypic characteristics (including metabolic and behavioural) affect both the intrauterine milieu and life-long health trajectories of their foetuses. Importantly, altered maternal nutrition, including both under- and over-nutrition, has been shown to lead to transgenerational transmission of metabolic disorders [14, 15]. Moreover, transmission of programming effects to subsequent generations can even be exerted in the absence of continued environmental stressors, thus perpetuating a cycle of obesity and metabolic disorders. Maternal malnutrition before as well as during pregnancy is associated with adverse childhood outcomes such as an increased susceptibility to obesity and related metabolic disorders in later life. Moreover, parental lifestyle factors prior to and at conception have also been shown recently to exert a powerful impact on the health of the offspring for more than one generation [16]. Transgenerational phenotype transmission is considered a form of epigenetic inheritance with evidence showing both germline and somatic inheritance of modifications leading to phenotype changes across generations.

\section{Nutritional Factors, Food and Eating}

Given the intimate association between food consumption and body weight, it is essential to consider whether food availability or some factor in the food culture could determine the level of obesity in a particular country. For the USA, it has been argued that changes in the energy flux (calculated from food availability data) over a 20-year period can account for the average increase in body weight of the population over the same period [17]. There is considerable evidence that exposure to particular types of foods or diets is associated with the overconsumption of energy and is a risk factor for weight gain. There is also evidence that portion size exerts an influence on the daily energy consumed. Other evidence draws attention to the snacking habit (uncompensated eating events between meals). The evidence does not point towards one single adverse pattern of eating. For example some reports indicate that a low meal frequency ( 2 vs. 5 eating episodes) is associated with obesity; other evidence indicates a strong influence of snacking (many eating episodes over the day). It can be agreed that under some conditions the presence in the food supply of energy-dense foods, access to highsugar beverages, specific eating habits and attitudes towards the body and foods can exert effects on specific individuals [18-20]. Good data exist for particular countries such as Poland $[21,22]$. Evidence exists in a sufficient number of countries to claim that national levels of obesity are related to differences in foods or eating. Research in this area is seriously hampered by a reliance on self-report measures of food intake which are known to be flawed and which may be the source of misleading impressions. Nevertheless, it remains highly plausible that a high energy intake (above and beyond metabolic needs) contributes strongly to the secular 
Blundell et al.: Variations in the Prevalence of Obesity Among European Countries, and a Consideration of Possible Causes

increase in obesity across the continent. Most countries support high fat eating habits within the food culture, and there is an increasing tendency to take sugary drinks (even in poorer countries). Whilst these factors can influence the pace of the epidemic, it is much more difficult to determine that specific 'toxic' food habits operate consistently and potently in every country. It is more likely that each country - because of its cultural values, local food habits, traditional foods, the economic milieu and attitudes towards food and health - has specific food-based risk factors [23, 24]. Future research can identify and compare at the national level specific high-risk foods or high-risk eating habits. Equally important will be the identification of food or eating-related factors that confer protection against over-consumption. One such factor could be the cultural retention of socially approved family-based meal taking, with rules that favour self-regulation of eating. One additional factor that often escapes attention is the consumption of alcohol. In some individuals alcohol contributes a significant portion of the daily energy intake, and this can be reflected at the national level. Depending on the cultural and religious rules about alcohol, this is likely to be a significant risk factor in some countries - but not in others. A comparison would be valuable. Indeed alcohol consumption has been shown in some population studies to be negatively associated to less obesity, despite its energy content and possible disinhibiting effects on appetite.

The issue of infant feeding has been of considerable research interest for more than half a century. Evidence suggests that breastfeeding may have a small protective effect against the later development of overweight and obesity, whereas partial breastfeeding does not. However, this issue is not easy to investigate or to resolve. One difficulty is that 'partial' breast feeding can include anything from 1 drop of breast milk to $99 \%$ of the child's milk intake. Whether the 'protective' effects of breastfeeding are attributable to breastfeeding itself or to other characteristics of mothers who chose to and are able to breastfeed is not, completely clear. In the absence of breastfeeding at young ages, the use of infant formulas may be problematic. There are now consistent data to indicate that a high level of protein intake in the first year of life can lead to weight gain [25]. This would have greater impact in those countries in which breastfeeding is discouraged (the converse would also apply). It was also reported in IDEFICS for Sweden that a culturally defined habit of providing a milk-cereal drink (Välling) in the early years of life was associated with weight gain [26]. This seems to be good evidence for the operation of an environmental risk factor operating specifically in one country.

It is also clear that in the area of food and eating, the commercial and industrial environment is influential. It is beyond debate that government policies are driven by the need to preserve economic growth. Food advertising forms part of the market, and there is evidence that exposure to unhealthy food advertising on both TV and the Internet is effective in promoting food consumption in children (but not in adults) [27]. Obese children may be particularly vulnerable to food advertisements [28]. Whether or not this factor contributes to the prevalence of obesity by operating with differential potency in different countries remains a matter for conjecture. The potency of food advertising is a function of both exposure (frequency of marketing message and the types of foods or beverages that are promoted) and power (the extent to which the message is persuasive, including the use of creative content techniques). Some data are available to indicate differences in food advertising prevalence on television across Europe [29]. However, there is a notable imbalance with extensive research conducted in the UK to indicate both the exposure and power of television food advertising (e.g. $[27,30]$ ) but notably less information available for other countries. Cross-European selfregulatory approaches have shown varied results in reducing children's exposure to TV food advertising; and statutory measures can achieve some reductions within this media [31]. However, it is important to note that in recent years, social media has become a key platform for behaviourally targeted, sophisticated, immersive and interactive digital marketing of high 
Blundell et al.: Variations in the Prevalence of Obesity Among European Countries, and a Consideration of Possible Causes

fat, sugar, salt (HFSS) foods, particularly to adolescents. Very little is known about the extent, nature and impact of this activity on food-related behaviours due to the inherent methodological and ethical challenges posed in attempting to access these data for research purposes. Nevertheless, the evidence base to support the impact of food advertising on children's eating behaviour draws attention to the need for clear policy guidelines at the European level and for increased surveillance and data gathering country by country.

\section{Are There Differences in Physiological Factors Operating between Countries?}

There are of course hundreds of physiological events or processes that can influence weight regulation and ultimately impact on obesity. There are also well defined physiological risk factors for obesity including fat: $\mathrm{CHO}$ oxidation rate, insulin resistance, glycaemic profile and even the volume and distribution of adipose tissue itself. Although a person's physiological profile has a certain influence on the susceptibility to weight gain, it is unlikely that such profiles are country-dependent. However, there is mounting evidence for the existence of metabolic phenotypes - clusters of metabolic functions that collectively constitute a higher risk of weight gain. Such phenotypes manifest an effect in interaction with particular dietary factors [32]. Indeed, it is hardly possible to separate physiological/metabolic influences from dietary influences; they should be considered together. The physiological phenotype is determined by many factors like genetic profile, microbiome and lifestyle factors; thus it is the resultant of a complex of factors. There exists therefore the possibility that for specific countries the dietary pattern could form a susceptibility factor in conjunction with a metabolic profile. In addition, metabolic flexibility is regarded as a meaningful influence. For example, the capacity to adapt to prevailing dietary conditions whilst avoiding the development of insulin resistance is of physiological benefit and leads to more healthy regulation [33]. The science of metabolomics is providing the possibility of molecular finger printing on a detailed scale using 'big data'. The use of combinations of domains of physiological data to predict risk factors such as the glycaemic response [34] is clearly an important concept. Although important for defining the risk of obesity at the individual level (in the field of personalised nutrition), it is unlikely that this approach can be called up to explain differences at the national level. As with other risk factors, the heterogeneity within a nation is likely to be much greater than average differences between countries.

However, it is clear that physiological processes, like genetic factors, exert their influence in interactions with other factors - such as the nutrient content of the diet. It is physiology that responds to the nutritional input, and therefore diet is crucial to an understanding of the impact of physiology on weight gain. An example is the impact of a high-fat diet in individuals with high liver insulin resistance [35]. In some countries the existence of large numbers of physiologically susceptible individuals would contribute to the overall level of obesity. Of course such individuals would have to be identified at the national level. This is a formidable task but is becoming more feasible due to analytical technology and computing power.

One issue that was mentioned in passing, but not developed in any detail, was the weight gain attributable to psychotropic medication. This is indeed an important issue with considerable evidence for the weight-inducing properties of antidepressants, minor tranquillizers (meprobamate and benzodiazepines) and neuroleptics such as the phenothiazines and the later second generation anti-psychotic drugs [36]. Beginning in the 1970s millions of prescriptions for these drugs have been written for millions of people. They have undoubtedly exerted an effect on the increasing adiposity of large numbers of citizens. The effect on fat accumulation is certainly due to physiological or neurochemical action of the drugs and therefore constitutes an effect of biology. However, the biological effects are selective to those indi- 
Blundell et al.: Variations in the Prevalence of Obesity Among European Countries, and a Consideration of Possible Causes

viduals receiving the drugs. This phenomenon can clearly exert an influence over statistical recording of obesity both temporally and geographically. Differing prescribing practices concerning mental health problems in different countries would certainly affect the numbers of people affected and the impact on the percentage of obesity. This is an issue that may affect prevalence rates and should be investigated more intensively. Mutatis mutandis, an analogous reasoning could be made for exposure to endocrine disruptors which has been increasing since a number of decades and shows considerable variation across countries

\section{Physical Activity and the Built Environment}

As mentioned earlier, it is conceivable that a factor such as nationally promoted cycling as a form of active daily transport for the majority of a population could operate as a strong protective factor against weight gain (and particularly fat gain). Equally, a lifestyle that embraces a high level of outdoor physical pursuits (such as skiing or cycling) could have similar effects. Countries such as Belgium, Netherlands, Denmark, Finland and Austria may benefit from such effects. With the rise in work-related technology over the last 70 years the amount of energy expended at work has markedly decreased. It has been proposed that the daily reduction in energy expenditure is sufficient to account for the upward trends in obesity in some countries (e.g. in the USA [37]). Consequently, there is considerable face validity in the proposition that low physical activity (and energy expenditure) is a risk factor for obesity that could account for some of the inter-country variance. However, it is clear that an apparently active lifestyle does not guarantee the absence of obesity within a country. Even those countries mentioned above with high levels of activity related to travel or leisure are still characterised by levels of obesity equivalent to 1 in every 5 adults. This is probably explained by two facts: first, not every person in a particular society conforms to the normative pattern of high activity, second even if they do it would still be possible to overcome this by a high food intake driven by a energy-dense diet. This indicates again - as we have seen many times - that one factor does not operate in isolation. The system is complex.

Research in this field benefits from the existence of a strong data base and the capacity to measure accurately (often objectively and quantitatively) the behavioural end point (physical activity or lack of it). There is consistent evidence that the amount of sedentary behaviour (or low physical activity) is associated with higher levels of body fat. European projects such as HELENA have contributed hugely to an understanding of physical activity and obesity [38]. This study indicated that adolescents with high levels of physical activity energy expenditure ate more food energy but were thinner than those with a lower level of physical activity. In this field, research benefits from the availability of instruments for the objective measurement of bodily activity (thereby reducing dependence on self-report). Tools such as Actigraph, ActivPal and Bodymedia Sensewear allow continual monitoring of movement and rest. 24-hour monitoring over 7-day periods have demonstrated significant positive associations between the amount of sedentary time and body fat mass, and an inverse relationship with the amount of moderate and vigorous activity [39]. These data support the idea of a bi-directional relationship; sedentariness promotes adipose tissue accumulation, and fatness deters physical activity.

European projects such as SPOTLIGHT have linked the physical environment with the potential to lead an active life. It should be noted that recent reviews have shown that the only two built environment factors that were consistently associated with weight outcomes are urban sprawl and land use. Using advanced, but freely available, technology such as the Google street view, neighbourhoods can be characterised according to their obesogenic characteristics and linked to specific levels of physical activity such as outdoor play or organised 
Blundell et al.: Variations in the Prevalence of Obesity Among European Countries, and a Consideration of Possible Causes

sports [40]. The link between a protective built environment, the potential to be active and the level of obesity is becoming clearer. Moreover, using mediation analysis it can be shown in European adults that the relationship between the types of neighbourhood (defined by residential density and SES) and obesity is mediated by energy balance behaviours such as food choice (fruit and vegetable consumption), habitual physical activity level, sedentary time and possibly sleep duration etc. [41].

It is possible to consider sleep as a component of the nychthemeral rhythm of activity and rest, but it is as a distinct biological entity that it appears to be associated with obesity. It has been estimated that between the years 1905 and 2008, the amount of sleep decreased by approximately $1 \mathrm{~h} /$ day. Approximately 15 years ago it was observed - somewhat paradoxically - that short sleep duration was associated with a high BMI. This is a fairly consistent finding although the effect size is variable. In the European project IDEFICS, the sleep duration of children has been associated with BMI in several European countries [42]. It is clear that children in different European countries have different sleep habits; for example, children in Spain tend to sleep fewer hours than in northern countries. A model linking sleep and obesity has implicated increased food intake and decreased physical activity as potential mediators [43]. To the extent that there are nationally (or culturally) defined rules regarding sleep, this feature could contribute to national differences in obesity - particularly as a risk factor in children.

\section{Overview}

The investigation of the causes underlying the variable prevalence of obesity in different countries of Europe poses important questions for the nature of obesity itself and our ability to manage the epidemic effectively. By giving a European wide dimension to the consideration of obesity, this has focussed attention on particular issues. In the arena of childhood obesity prevails a view that the environment (or culture) is causing children to become fat. In principle the environmental agents should be modifiable. However, once obesity has become established, it can promote further weight gain and is extremely difficult to resist. An analysis of the diversity within Europe questions whether the 'remedy' should be sought on a pan-European basis - as a uniform policy rolled out across all countries. Alternatively one could advocate separate strategies for each country. This workshop has identified certain risk factors for obesity that appear to be ubiquitous, that transcend national boundaries and that operate in the dense network of interconnections between biology and culture. However, there are also indications that specific risk factors operate with selective potency in particular countries. These should form a part of national initiatives. Obesity is not a desired or wanted condition; it appears to 'happen'. It is therefore necessary to be specific about the factors that maintain unwanted levels of adipose tissue in the body. This workshop has contributed to the development of The Obesity Scorecard and has demonstrated that it can be a valuable tool to throw light on the European dimension of obesity. The Scorecard is currently a work in progress and requires funding to take it to the next phase. It is also apparent that, because of the multi-dimensional nature of obesity, any systematic approach to change lifestyle should go beyond the issue of bodily fatness and extend into areas of other non-communicable diseases.

\section{Disclosure Statement}

The authors reported no conflict of interest. 
Blundell et al.: Variations in the Prevalence of Obesity Among European Countries, and a Consideration of Possible Causes

\section{References}

1 Global Health Observatory: Obesity: Data by Country. Geneva, World Health Organization, 2014. www.who. int/gho/ncd/risk_factors/overweight/en/(last accessed January 24, 2017).

2 UK Government's Foresight Programme: Foresight. Tackling Obesities: Future Choices - Obesity System Atlas. Government Office for Science, 2007. www.gov.uk/government/publications/reducing-obesity-obesity-systemmap ((last accessed January 24, 2017).

-3 Finegood DT, Merth TD, Rutter H: Implications of the foresight obesity system map for solutions to childhood obesity. Obesity (Silver Spring) 2010;18(suppl 1):S13-16.

4 Blundell JE, Dulloo AG, Salvador J, Fruhbeck G: Beyond BMI - phenotyping the obesities. Obes Facts 2014;7: 322-328.

$>5$ Stommel M, Schoenborn CA: Accuracy and usefulness of BMI measures based on self-reported weight and height: Findings from the NHANES \& NHIS 2001-2006. BMC Public Health 2009;9:421.

-6 Wijnhoven TM, van Raaij JM, Spinelli A, Rito AI, Hovengen R, Kunesova M, Starc G, Rutter H, Sjoberg A, Petrauskiene A, O’Dwyer U, Petrova S, Farrugia Sant'angelo V, Wauters M, Yngve A, Rubana IM, Breda J: WHO European childhood obesity surveillance initiative 2008: weight, height and body mass index in 6-9-year-old children. Pediatr Obes 2013;8:79-97.

7 Olsen LW, Baker JL, Holst C, Sorensen TI: Birth cohort effect on the obesity epidemic in Denmark. Epidemiology 2006;17:292-295.

8 Lissner L, Sohlstrom A, Sundblom E, Sjoberg A: Trends in overweight and obesity in Swedish schoolchildren 1999-2005: has the epidemic reached a plateau? Obes Rev 2010;11:553-559.

-9 Olds T, Maher C, Zumin S, Peneau S, Lioret S, Castetbon K, Bellisle, de Wilde J, Hohepa M, Maddison R, Lissner L, Sjoberg A, Zimmermann M, Aeberli I, Ogden C, Flegal K, Summerbell C: Evidence that the prevalence of childhood overweight is plateauing: data from nine countries. Int J Pediatr Obes 2011;6:342-360.

$\rightarrow 10$ Locke AE, Kahali B, Berndt SI, et al: Genetic studies of body mass index yield new insights for obesity biology. Nature 2015;518:197-206.

-11 Vimaleswaran KS, Li S, Zhao JH, Luan J, Bingham SA, Khaw KT, Ekelund U, Wareham NJ, Loos RJ: Physical activity attenuates the body mass index-increasing influence of genetic variation in the FTO gene. Am J Clin Nutr 2009;90:425-428.

12 Lu Y, Loos RJ: Obesity genomics: assessing the transferability of susceptibility loci across diverse populations. Genome Med 2013;5:55.

13 Robinson MR, Hemani G, Medina-Gomez C, Mezzavilla M, Esko T, Shakhbazov K, Powell JE, Vinkhuyzen A, Berndt SI, Gustafsson S, Justice AE, Kahali B, Locke AE, Pers TH, Vedantam S, Wood AR, van Rheenen W, Andreassen OA, Gasparini P, Metspalu A, Berg LH, Veldink JH, Rivadeneira F, Werge TM, Abecasis GR, Boomsma DI, Chasman DI, de Geus EJ, Frayling TM, Hirschhorn JN, Hottenga JJ, Ingelsson E, Loos RJ, Magnusson PK, Martin NG, Montgomery GW, North KE, Pedersen NL, Spector TD, Speliotes EK, Goddard ME, Yang J, Visscher PM: Population genetic differentiation of height and body mass index across Europe. Nat Genet 2015;47:13571362.

14 Vickers MH: Developmental programming and transgenerational transmission of obesity. Ann Nutr Metab 2014;64(suppl 1):26-34.

15 Ozanne SE: Epigenetic signatures of obesity. N Engl J Med 2015;372:973-974.

16 Lane M, Zander-Fox DL, Robker RL, McPherson NO: Peri-conception parental obesity, reproductive health, and transgenerational impacts. Trends Endocrinol Metab 2015;26:84-90.

17 Swinburn B, Sacks G, Ravussin E: Increased food energy supply is more than sufficient to explain the US epidemic of obesity. Am J Clin Nutr 2009;90:1453-1456.

-18 Swinburn BA, Caterson I, Seidell JC, James WP: Diet, nutrition and the prevention of excess weight gain and obesity. Public Health Nutr 2004;7:123-146.

19 Malik VS, Pan A, Willett WC, Hu FB: Sugar-sweetened beverages and weight gain in children and adults: a systematic review and meta-analysis. Am J Clin Nutr 2013;98:1084-1102.

-20 Naska A, Katsoulis M, Orfanos P, Lachat C, Gedrich K, Rodrigues SS, Freisling H, Kolsteren P, Engeset D, Lopes C, Elmadfa I, Wendt A, Knuppel S, Turrini A, Tumino R, Ocke MC, Sekula W, Nilsson LM, Key T, Trichopoulou A: Eating out is different from eating at home among individuals who occasionally eat out. A cross-sectional study among middle-aged adults from eleven European countries. Br J Nutr 2015;113:1951-1964.

21 Charzewska J, Chwojnowska Z, Wajszczyk B, Chabros E: Twenty four year time trends in fats and cholesterol intake by adolescents. Warsaw Adolescents Study. Anthropol Rev 2015;78:183-195.

22 Charzewska J, Kulesza W, Brzezinska J, Chwojnowska Z: Relationship between obesity or overweight development and the frequency of meals, their distribution during the day and consumption of atherogenic food products. Zywienie Czlowieka 1981;8:217-227.

23 Stefler D, Pajak A, Malyutina S, Kubinova R, Bobak M, Brunner EJ: Comparison of food and nutrient intakes between cohorts of the HAPIEE and Whitehall II studies. Eur J Public Health 2016;26:628-634.

-24 Lakerveld J, Rebah MB, Mackenbach JD, Charreire H, Compernolle S, Glonti K, Bardos H, Rutter H, De Bourdeaudhuij I, Brug J: Obesity-related behaviours and BMI in five urban regions across Europe: sampling design and results from the SPOTLIGHT cross-sectional survey. BMJ open 2015;5:e008505.

25 Koletzko BV, Shamir R: Infant formula: does one size fit all? Curr Opin Clin Nutr Metab Care 2016;19:205-207. 
Blundell et al.: Variations in the Prevalence of Obesity Among European Countries, and a Consideration of Possible Causes

26 Wiberger M, Eiben G, Lissner L, Mehlig K, Papoutsou S, Hunsberger M: Children consuming milk cereal drink are at increased risk for overweight: the IDEFICS Sweden study, on behalf of the IDEFICS consortium. Scand J Public Health 2014;42:518-524.

27 Boyland EJ, Harrold JA, Kirkham TC, Halford JC: Persuasive techniques used in television advertisements to market foods to UK children. Appetite 2012;58:658-664.

28 Halford JC, Boyland EJ, Hughes GM, Stacey L, McKean S, Dovey TM: Beyond-brand effect of television food advertisements on food choice in children: the effects of weight status. Public Health Nutr 2008;11:897-904.

29 Kelly B, Halford JC, Boyland EJ, Chapman K, Bautista-Castano I, Berg C, Caroli M, Cook B, Coutinho JG, Effertz T, Grammatikaki E, Keller K, Leung R, Manios Y, Monteiro R, Pedley C, Prell H, Raine K, Recine E, Serra-Majem L, Singh S, Summerbell C: Television food advertising to children: a global perspective. Am J Public Health 2010;100:1730-1736.

-30 Boyland EJ, Harrold JA, Kirkham TC, Corker C, Cuddy J, Evans D, Dovey TM, Lawton CL, Blundell JE, Halford JC: Food commercials increase preference for energy-dense foods, particularly in children who watch more television. Pediatrics 2011;128:e93-100.

31 Boyland EJ, Harrold JA, Kirkham TC, Halford JC: The extent of food advertising to children on UK television in 2008. Int J Pediatr Obes 2011;6:455-461.

-32 Martinez JA, Navas-Carretero S, Saris WH, Astrup A: Personalized weight loss strategies-the role of macronutrient distribution. Nat Rev Endocrinol 2014;10:749-760.

33 Corpeleijn E, Saris WHM, Blaak EE: Metabolic flexibility in the development of insulin resistance and type 2 diabetes: effects of lifestyle. Obes Rev 2009;10:178-193.

-34 Zeevi D, Korem T, Zmora N, Israeli D, Rothschild D, Weinberger A, Ben-Yacov O, Lador D, Avnit-Sagi T, LotanPompan M, Suez J, Mahdi JA, Matot E, Malka G, Kosower N, Rein M, Zilberman-Schapira G, Dohnalova L, Pevsner-Fischer M, Bikovsky R, Halpern Z, Elinav E, Segal E: Personalized nutrition by prediction of glycemic responses. Cell 2015;163:1079-1094.

-35 Yubero-Serrano EM, Delgado-Lista J, Tierney AC, Perez-Martinez P, Garcia-Rios A, Alcala-Diaz JF, Castano JP, Tinahones FJ, Drevon CA, Defoort C, Blaak EE, Dembinska-Kiec A, Riserus U, Lovegrove JA, Perez-Jimenez F, Roche HM, Lopez-Miranda J: Insulin resistance determines a differential response to changes in dietary fat modification on metabolic syndrome risk factors: the LIPGENE study. Am J Clin Nutr 2015;102:1509-1517.

-36 Bray GA, Fruhbeck G, Ryan DH, Wilding JP: Management of obesity. Lancet 2016;387:1947-1956.

-37 Church TS, Thomas DM, Tudor-Locke C, Katzmarzyk PT, Earnest CP, Rodarte RQ, Martin CK, Blair SN, Bouchard C: Trends over 5 decades in US occupation-related physical activity and their associations with obesity. PLoS One 2011;6:e19657.

-38 Cuenca-García M, Ortega FB, Ruiz JR, Labayen I, Moreno LA, Patterson E, Vicente-Rodríguez G, González-Gross M, Marcos A, Polito A: More physically active and leaner adolescents have higher energy intake. J Pediatr 2014; 164:159-166. e152.

-39 Myers A, Gibbons C, Finlayson G, Blundell J: Associations among sedentary and active behaviours, body fat and appetite dysregulation: investigating the myth of physical inactivity and obesity. Br J Sports Med 2016

40 Charreire H, Mackenbach JD, Ouasti M, Lakerveld J, Compernolle S, Ben-Rebah M, McKee M, Brug J, Rutter H, Oppert J-M: Using remote sensing to define environmental characteristics related to physical activity and dietary behaviours: a systematic review (the SPOTLIGHT project). Health Place 2014;25:1-9.

41 Compernolle S, Oppert J-M, Mackenbach JD, Lakerveld J, Charreire H, Glonti K, Bardos H, Rutter H, De Cocker $\mathrm{K}$, Cardon G: Mediating role of energy-balance related behaviors in the association of neighborhood socioeconomic status and residential area density with BMI: the SPOTLIGHT study. Prev Med 2016;86:84-91.

42 Hense S, Pohlabeln H, De Henauw S, Eiben G, Molnar D, Moreno LA, Barba G, Hadjigeorgiou C, Veidebaum T, Ahrens W: Sleep duration and overweight in European children: is the association modified by geographic region? Sleep 2011;34:885-890.

43 Patel SR, Hu FB: Short sleep duration and weight gain: a systematic review. Obesity (Silver Spring) 2008;16: 643-653. 


\section{Erratum}

In the article by Blundell JE, Baker JL, Boyland E, Blaak E, Charzewska J, de Henauw S, Frühbeck G, Gonzalez-Gross M, Hebebrand J, Holm L, Kriaucioniene V, Lissner L, Oppert JM, Schindler K, Silva AM, Woodward E: Variations in the Prevalence of Obesity Among European Countries, and a Consideration of Possible Causes. Obes Facts 2017;10:25-37 the author list is incorrect.

The correct author list is as follows:

John E. Blundell ${ }^{a}$ Jennifer Lyn Baker ${ }^{b} \quad$ Emma Boyland $^{c} \quad$ Ellen Blaak $^{d}$ Jadwiga Charzewska ${ }^{e}$ Stefaan de Henauw ${ }^{f}$ Gema Frühbeck $^{g}$ Marcela Gonzalez-Gross ${ }^{\mathrm{h}}$ Johannes Hebebrand ${ }^{i}$ Lotte Holm ${ }^{j} \quad$ Vilma Kriaucioniene $^{k} \quad$ Lauren Lissner $^{l}$ Jean-Michel Oppert ${ }^{m} \quad$ Karin Schindler $^{n} \quad$ Ana Lúcia Silva $^{\circ} \quad$ Euan Woodward $^{p}$ 